\title{
Gas exchange during storage and incubation of Avian eggs: effects on embryogenesis, hatchability, chick quality and post-hatch growth
}

\author{
O. ONAGBESAN*, V. BRUGGEMAN, L. DE SMIT, M. DEBONNE, A. WITTERS, \\ K. TONA, N. EVERAERT and E. DECUYPERE \\ Laboratory for Physiology and Immunology of Domestic Animals, Catholic \\ University, Kasteelpark Arenberg 30, Heverlee, B-3001 Belgium \\ *Corresponding author: Okanlawon.onagbesan@biw.kuleuven.be
}

\begin{abstract}
Embryonic development is a dynamic process that requires a fine balance between several factors in order to achieve an optimum hatchability and chick quality. These factors include the background of the embryo, such as genetic line of the breeders, the age of the breeder, egg weight, and factors related to the environment in which the egg is stored and incubated, such as temperature, humidity, gas levels and altitude. Gas exchanges are of fundamental importance for embryonic development during incubation and may affect the livability of the embryo. This paper reviews the roles of the gaseous environment (i.e. $\mathrm{O}_{2}$ and $\mathrm{CO}_{2}$ ) around hatching eggs during storage and during incubation and the effect it might have on the survival of the developing embryos and the chicks that hatch. The state of the art on the different attempts to establish the optimum requirements of different gases that promote the optimal developmental trajectories at different periods during incubation is presented. The roles and consequences of different levels of $\mathrm{O}_{2}$ and $\mathrm{CO}_{2}$ during storage and incubation on hatchability, incubation duration, hatching process, embryo growth, embryo mortality, organ development and morphology, metabolism, blood acid-base balance, chick quality and chick post-hatch growth are reviewed.
\end{abstract}

Keywords: gas exchange; avian eggs; storage; incubation; embryogenesis; chick quality; post-hatch growth

\section{Introduction}

Hatching eggs from chickens require interactions between several factors to promote the development of the embryo and hatch at the appropriate duration for incubation. These factors include the background of the embryo, such as genetic line of the breeders, the age of the breeder, the egg weight, and factors related to the environment in which the egg is

(C) World's Poultry Science Association 2007

World's Poultry Science Journal, Vol. 63, December 2007

Received for publication February 12, 2007

Accepted for publication May 17, 2007 


\section{Role of gaseous exchange in egg storage and incubation: O. Onagbesan et al.}

stored and incubated, such as temperature, humidity, gas levels and altitude. Egg handling such as turning also has some effects. Embryonic development is a dynamic process that requires a fine balance between these environmental factors in order to achieve an optimum hatchability and chick quality. Because there are differences in the quality of hatching eggs from different lines of breeders, breeders of different ages, eggs stored under different conditions or even eggs of different weights, it is becoming apparent that different eggs may require different incubation conditions. Recent studies also suggest that gas requirements of developing embryos change during incubation. Thus incubation procedures and incubator designs are now being modified to fulfill these requirements for optimal hatchability.

This paper reviews the roles of the gaseous environment around hatching eggs during storage and during incubation and the effect it might have on the survival of the developing embryos, the hatchability of the eggs and the quality of the chicks hatched. Gas exchanges are of fundamental importance for embryonic development during incubation and may affect the livability of the embryo (Tullett, 1990). The exchange of incubation gases is facilitated by the chorioallantoic membrane (CAM), which is a highly vascular structure in conjunction with the porosity of the egg shell. These two structures however permit the diffusion of oxygen $\left(\mathrm{O}_{2}\right)$ and carbon dioxide $\left(\mathrm{CO}_{2}\right)$ between the environment and the blood of the embryo (Tullett and Deeming, 1982). During incubation, the egg loses water through the membranes and this culminates in the formation of the air cell between the inner and outer membranes underneath the eggshell at the blunt end of the egg. At internal pipping, the embryo pierces into the air cell through the membrane to gain access to air so that pulmonary ventilation becomes an additional route for gas exchange (Vince and Salter, 1967; El-Ibiary et al., 1966) until the rupture of the eggshell (external pipping) when full pulmonary ventilation is established. Several studies on the chicken have attempted to establish the optimum requirement of different gases that promote the optimal developmental trajectories at different periods during incubation. Using the chicken as a primary example in the following sections (except otherwise stated), the roles of the eggshell and the CAM in gas exchange between the external and internal environment of the egg, the optimal requirements and the effects of $\mathrm{O}_{2}$ and $\mathrm{CO}_{2}$ on embryonic development, hatchability and chick quality will also be reviewed.

\section{The role of the eggshell in gas exchange}

The avian eggshell forms the barrier between the internal and external environment of the egg. Its structure has been comprehensively described by Tullet (1984). It protects the embryo mechanically against impacts and serves as a barrier against bacterial infection. The inner side of the shell serves as a source of calcium for the development of embryonic bones (Romanoff, 1960). An important feature of the eggshell is its porosity. The avian embryo respires by exchanging oxygen and carbon dioxide across the pores in the eggshell. The pores also provide escape route for water vapour.

Romanoff and Romanoff, (1949), Wangensteen and Rahn, (1970-71), Ar et al. (1974) have demonstrated that gases and water vapour are exchanged between the internal and external environments of the egg through the pores in the eggshell according to simple laws of diffusion (Fick's law).

Rahn, (1981) and Rahn et al. (1981) have provide evidence that it is the shell conductance that determines the precise amount of $\mathrm{O}_{2}, \mathrm{CO}_{2}$ and water vapour that is exchanged between the internal and external environment of the egg. Thus diffusive conductance of gases, in and out of the egg, increases if pores are more numerous, wider and shorter. As shell porosity decreases, the amount of $\mathrm{CO}_{2}$ that escapes across the shell is 
Role of gaseous exchange in egg storage and incubation: O. Onagbesan et al.

reduced. Ar et al. (1974) have reported that egg shell conductance increases with egg weight since larger eggs have more porous shells. Tullet, $(1979,1981)$ also reported a wide variation in shell porosity between eggs of different hens. Typically the pore numbers in domestic hen range between 7,000 and 17,000 (Solomon, 1991).

Differences in eggshell conductance has been ascribed to differences in age of parent stock, as older parents produce eggs of higher shell conductance (Peebles and Brake, 1987; Kirk et al., 1980; Hamilton, 1978; Roque and Soares, 1994). Other factors are ambient temperature (Bamelis, 2003), and feed composition (Hurwitz, 1987). Thus, in order to create optimum gas exchange in the embryonic environment, Visschedijk (1991) suggested that the functional conductance of the eggshell must be considered along with the gaseous composition and barometric pressure of the ambient fresh air, the incubator ventilation rate and the embryonic $\mathrm{O}_{2}$ uptake.

Several studies have reported the consequences that eggshell conductance can have on embryonic development during incubation. Tullett and Deeming (1982) reported that low porosity limits embryonic respiration and Burton and Tullett (1983) showed that this results in lower growth rate. The metabolic rate of the embryo increases during the second half of incubation and thus is the oxygen requirement. $\mathrm{O}_{2}$ supply is limited by the conductance of the shell and other physiological characteristics of the embryo. The result is a plateau phase of $\mathrm{O}_{2}$ input and $\mathrm{CO}_{2}$ output. Bamelis et al. (2001) reported that this phase is reached earlier in eggs with lower eggshell conductance (especially eggs from young breeders).

Burton et al. (1989), reported that air cell $\mathrm{pO}_{2}$, just before pipping, increases with increasing conductance of the eggshell and the reverse is true for $\mathrm{pCO}_{2}$. With increasing conductance of the shell, pipping by embryos is delayed. Hatchability has also been reported to be inversely related to eggshell conductance. Eggs with the lowest eggshell conductance achieve the highest hatchability irrespective of the age of the parent stock (McDaniel et al., 1979; Roque and Soares, 1994; Visschedijk, 1968b). The stage of embryonic mortality has been related to eggshell conductance; late embryonic mortality is higher in eggs with high eggshell conductance (Bamelis, 2003).

\section{The role of yolk sac membrane and cam in gas exchange}

Gas exchange between the embryo and the air diffused into the egg takes place through specialized and highly vascularized embryonic organs. During early incubation, the yolk sac membrane is the respiratory organ. Later, at d 5 of incubation of chicken eggs, the CAM which is a fusion of the chorion and allantois, starts to develop to assume the respiratory function of the embryo. By d 11 of incubation, the CAM is fully developed lying attached under most of the inner eggshell membrane and fully functional (Romanoff, 1960). The gas fluxes between the embryo and the environment depend on 1) the gas partial pressures in the blood of the extra-embryonic circulation, 2) the effective gas exchange area and 3) the thickness and diffusive properties of the material separating the red blood cells from the environment.

The primary gas transport system of the yolk sac membrane begins to function after the onset of circulation at d 2 of incubation. Meuer and Baumann (1988) showed that the major part of the diffusion resistance between the environment and the gas vessels at this period is provided by the albumen layer that separates the yolk sac from the inner shell membrane. The low $\mathrm{pO}_{2}$ values in the intraembryonic venous vessels of young embryos at $\mathrm{d} 4-\mathrm{d} 6$ further suggest that the gas transport system is working at the limit of its capacity and could be determinative for early embryonic development.

When the allantoic sac develops and fuses with the chorion (at about d 8), respiratory 
Role of gaseous exchange in egg storage and incubation: O. Onagbesan et al.

function is successively transferred to the blood vessels of the newly formed CAM. The outer surface of the organ forms a very dense capillary bed. Dusseau and Hutchins (1988) studied the vascular density of the CAM in chicken eggs with time from $\mathrm{d} 7$ and found an increase in CAM vascular density index (VDI) of $36 \%$ and $68 \%$ on d 10 and d 14 respectively. They also found that $\mathrm{O}_{2}$ supply significantly influenced the VDI. Strict et al. (1991), incubated chicken eggs in 12, 16, 21, 45 and $70 \% \mathrm{O}_{2}$ from d 7 to $\mathrm{d} 14$ and showed that the graded exposure to $\mathrm{O}_{2}$ produced a dose-dependent change in VDI. Hypoxia increased and hyperoxia decreased VDI. The CAM attains its maximal growth at d 14-16 and corresponds to the time of the maximal growth rate of the embryo (Romanoff, 1967; Dietz et al., 1998). From this period, other mechanisms such as increased CAM blood flow and blood oxygen affinity (Tazawa, 1980) and the movement of the blood capillaries to a position nearer the inner shell membrane (Dunker, 1978), enhance oxygen delivery rate. Several studies (Paganelli et al., 1988; Visschedijk, 1968a; Seymour and Visschedijk, 1988; Reizis et al., 2005) have shown that respiratory gas exchange is higher in the portion of the CAM under the air cell. This has been related to the greater porosity and conductance of the shell in the blunt end of the egg where the air cell is formed.

\section{The role of oxygen}

\section{OXYGEN REQUIREMENT AND ITS EFFECTS DURING PRE-INCUBATION PERIOD}

Oxygen is the gas that drives the metabolic machinery of the embryonic cells in order to execute the complex manoevers of development (Rahn and Ar, 1979). Before incubation, hatching eggs are usually stored for some days after lay. Few studies have actually demonstrated, directly, the effects of $\mathrm{O}_{2}$ on the egg during the storage period. Proudfoot $(1964,1965)$ demonstrated that storing eggs in high concentrations of air is detrimental to hatchability. In other studies where eggs were stored in closed environments such as plastic bags of different permeability, it was shown that the gaseous environment of the egg during storage influenced egg quality and the hatchability of eggs (Becker, 1964; Becker et al., 1964; Proudfoot, 1963; Bose and Stewart, 1948 : Rutherford and Murray, 1963; Goodwin et al., 1962; Fletcher et al., 1958).

In another experiment where eggs were stored unpackaged or packaged in cryovac bags before incubation, Becker et al. (1968) concluded that there may be an optimal level of $\mathrm{CO}_{2}$ and $\mathrm{O}_{2}$ for the embryos prior to incubation and that these levels are different from that in air. These studies suggest that egg storage in air before incubation increases the loss of $\mathrm{CO}_{2}$ from the egg, increases albumen $\mathrm{pH}$, decreases Haugh units, increases water loss and inevitably lowers hatchability of eggs and prolongs hatching time. However, it is not absolutely clear whether these effects are directly the effect of oxygen in air or the loss of water from the egg during storage. The reports of Hinton (1968) and Walsh et al. (1995) concluded that a requirement for long-term storage of eggs was the prevention of water loss from the egg to avert a delay in embryonic development, early embryonic mortality, extensions of incubation duration (Mather and Laughlin, 1976; 1979) and a decline in hatchability. The studies of Becker et al. $(1964 ; 1968)$ using chickens and turkey eggs reported that the effects of water loss are only apparent if eggs are stored for over 8 days. Thus the effect observed on egg quality parameters and hatchability when eggs are stored in air unpackaged for up to 7 days is most likely to be related to gas exchanges in the environment of the egg.

\section{OXYGEN REQUIREMENT AND ITS EFFECTS DURING INCUBATION PERIOD}


Role of gaseous exchange in egg storage and incubation: O. Onagbesan et al.

During incubation, the oxygen uptake of the avian egg increases exponentially as the embryo grows rapidly during the first two weeks (Tazawa, 1980; Vleck et al., 1979; Gefen and $\mathrm{Ar}, 2001)$. In practice, chicken eggs are currently incubated in a gaseous environment of $21 \% \mathrm{O}_{2}$ in the presence of $\mathrm{CO}_{2}$ that may be up to $0.5 \%$ at varying periods during incubation to achieve optimum embryo development and hatchability. Incubator ventilation is designed to provide adequate $\mathrm{O}_{2}$ to the embryo and eliminate excessive $\mathrm{CO}_{2}$ from the incubator. In this part of the review, the effects of hypoxia and hyperoxia will be discussed.

In nature, $\mathrm{O}_{2}$ supply varies with altitude and thus the possibility for the occurrence of a condition of hypoxia is a reality. Oxygen supply decreases with high altitudes and influences incubation duration and hatchability (Visschedijk, 1985; Hassanzadeh et al. 2002). Smith et al. (1969) showed that incubating eggs at high altitude retards embryo growth. As the oxygen level decreases with altitude, its requirement and consumption by the embryos might decline as a result of adaptation leading usually to shorter incubation duration and early hatch (Julian, 2000; Hassanzadeh et al., 2004). The aetiology of ascites in broiler chickens has been linked to differences in the oxygen requirements of fast and slow growing lines of chickens during the incubation period (Peacock et al., 1990; Julian, 1993, 2000; Hassanzadeh et al., 2004).

\section{Effects on hatching process and hatchability}

Several studies have investigated the requirements for $\mathrm{O}_{2}$ at different stages of incubation and their effects on embryo development, hatching process and hatchability (Cruz and Romanoff, 1944; Taylor et al., 1956; Dzialowski et al., 2002; Altimiras and Phu, 2000; Chan and Burggren, 2005; McCutcheon et al., 1962; Stock and Metcalfe, 1987; Stock et al., 1983; Strick et al., 1991). Chronic and acute hypoxia or hyperoxia have been reported to influence the development of chick embryo and hatchability differentially and their effect may depend on the timing of their application during incubation.

The early studies of Cruz and Romanoff (1944) and Taylor et al. (1956), show that chick embryos are very sensitive to $\mathrm{O}_{2}$ deprivation during early incubation. $\mathrm{O}_{2}$ levels below $18 \%$, applied during the first 5 days of incubation depressed hatchability relative to the level of $\mathrm{O}_{2}$ deprivation. At levels below $10 \%$ (corresponding to acute hypoxia) significant embryo mortality was recorded. The authors also reported that chick embryos can tolerate $\mathrm{O}_{2}$ levels up to $60-79 \%$ beyond which hatchability becomes depressed. In contrast to short-term exposure, Barott (1937) reported that continuous exposure to $\mathrm{O}_{2}$ levels of 30$50 \%$ throughout incubation decreased hatchability. These two contrasting results suggest that high $\mathrm{O}_{2}$ levels may be beneficial or detrimental at certain developmental windows during incubation.

Oxygen requirements during the mid-incubation period (5-8 days and 9-12 days) have been studied by Taylor and Kreutziger $(1965,1966) . \mathrm{O}_{2}$ levels below $15 \%$ depressed hatchability similar to that at day $1-5$, the effect becoming acute at about $12.5 \%$. This suggests a better tolerance to acute hypoxia with increasing age of the embryo. At day 5 $8, \mathrm{O}_{2}$ levels above $45 \%$ were detrimental to hatchability of embryos. Tolerance level increased to $60-65 \%$ at day 9-12 suggesting that the high $\mathrm{O}_{2}$ tolerance of the embryos shifts as the embryo grows during mid incubation. Similar shifts in $\mathrm{O}_{2}$ tolerance had earlier been reported by other researchers (Barrot, 1937; Saddler et al., 1954; Riddle, 1924; Remotti, 1933).

The tolerance of embryos to hyperoxia increases further between d 13 and d 16 of incubation when tolerance level can be as high as 85\% (Taylor and Kreutziger, 1969) with no effect on hatchability. Stock et al. $(1983,1985)$ reported enhancing effect of hyperoxia of up to $70 \%$ on embryo growth at d $13-\mathrm{d} 16$. Between d16 and d18, the tolerance of the 
Role of gaseous exchange in egg storage and incubation: O. Onagbesan et al.

embryo to hyperoxia shifts again to a lower level. Taylor et al. (1971) reported a tolerance level of up 50\% with higher levels resulting in significant reduction in hatchability. Similarly, Stock et al. $(1983,1985)$ reported an enhanced embryo growth but that the effect of $70 \% \mathrm{O}_{2}$ was less than that obtained with 40 or $60 \% \mathrm{O}_{2}$. As in the earlier stages of development, $\mathrm{O}_{2}$ levels lower than $16 \%$ reduced hatchability and embryo growth (Taylor et al., 1971; Stock and Metcalfe, 1987).

\section{Physiological, morphological and metabolic effects}

Early indications as to how $\mathrm{O}_{2}$ might influence the physiological processes involved in embryo development came from the studies of Remoti (1933) in which he observed that exposure to varying levels of $\mathrm{O}_{2}$ had effect on the vascularity and the density of the allantoic membrane. More recent studies have also affirmed that $\mathrm{O}_{2}$ levels during incubation influence the morphological and physiological aspects of embryo development (Chan and Burggren, 2005; Altimiras and Phu, 2000; Dzialowski et al., 2002; Burton and Palmer, 1992; Hopes and Jahn, 1995; Strick et al., 1991).

\section{Embryo growth}

Several studies have shown reduced survivability during early development due to the effect of hypoxia on metabolism and growth of the embryo (Sharma et al., 2006; Ruijtenbeek et al., 2003; Altimiras and Phu, 2000) suggesting that a threshold of $\mathrm{O}_{2}$ availability is required to initiate and sustain early embryo development. Some studies suggest that chronic hypoxia reduces the body mass of the embryo whether it is applied during early, mid or late in development (McCutcheon et al., 1982; Stock and Metcalfe, 1987; Burton and Palmer, 1992; Rouwet et al., 2002; Dzialowski et al., 2002; Sharma et al., 2006; Villamor et al., 2004) whereas others found no changes (Chan and Burggren, 2005; Altimiras and Phu, 2000). The studies of Stock et al. (1983, 1985), Stock and Metcalfe (1987), clearly showed that hyperoxia during the second half of incubation is beneficial to the growth of the embryo. $\mathrm{O}_{2}$ demand increases during the latter part of incubation due to increased metabolic activities. The findings of Stock et al. tend to support a hypothesis that $\mathrm{O}_{2}$ availability at this period limits growth and metabolism of chick embryos incubated under normoxic conditions as currently practiced. Physiological parameters such as embryo metabolism show a decrease under hypoxia (Dzialowski et al., 2002; Stock and Metcalfe, 1987), without a change in $\mathrm{T}_{3}$ but higher corticosterone level (Blacker et al., 2004) suggesting that embryos under hypoxic conditions may be under stress.

\section{CAM development}

Strick et al. (1991) reported that CAM development was inversely related to the level of $\mathrm{O}_{2}$ supplied during mid-incubation (7-14 days). Data from the reports of Chan and Burggren (2005), Richards et al. (1991), Hoper and Jahn (1995) show that chronic hypoxia enhances the vascularity and the weight of the area vasculosa when applied early or late during incubation but depresses its growth if applied throughout the duration of incubation (Burton and Palmer, 1992). Conversely, hyperoxia decreases the vascularity of the area vasculosa and weight of the CAM (Strick et al., 1991; Hoper and Jahn, 1995). This seems rather incompatible with the growth promoting effects of hyperoxia as growth requires adequate vascular distribution of nutrients.

\section{Cardiovascular system}

After 4 days of incubation, the chick embryo reaches a critical mass that requires cardiac function and intravascular blood flow for nutrient delivery for metabolic activities. Many studies have shown that hypoxia impairs cardiovascular development and function. 
Role of gaseous exchange in egg storage and incubation: O. Onagbesan et al.

Reports are conflicting about heart mass. It has been variously reported to increase (Stock and Metcalfe, 1987; Rouwet et al., 2002; McCutcheon et al., 1982), remain unchanged (Dzialowski et al., 2002, Altimiras and Phu, 2000; Chan and Burggren, 2005) or decrease (Richards et al., 1991) when embryos were exposed to hypoxia. However, heart defects that alter heart rates and detrimental vascular remodeling that impair arterial pressure have consistently been reported (Sharma et al., 2006; Tobita and Keller, 2000; Ruckman et al., 1985; Villamor et al., 2004; Crossley et al., 2003; Haring et al., 1970).

\section{Brain and lungs}

Other organs have also been reported to be affected by hypoxic incubation. Brain weight decreased (Stock and Metcalfe, 1987; Richards et al., 1991) or remained unchanged (Assom-Batres et al., 1989; Chan and Burggren, 2005; Ruijtenbeek et al., 2003) when applied in the last third of incubation. Lung to body mass ratio increased (Xu and Mortola, 1989) and the development of lung surfactant system is advanced (Blacker et al., 2004) when applied towards the last days of incubation. It can also advance the switch from embryonic to adult haemoglobin (Hb) (Baumann et al., 1983) or alter haematocrit levels (Xy and Mortola, 1989). These changes in lung functions under hypoxic conditions enhance the transition to pulmonary ventilation and early hatching.

\section{Ascites in broiler chickens}

In broilers, hypoxia during the last stages of incubation is associated with the incidence of ascites (Decuypere, 2002). Structural changes in the cardiovascular and pulmonary systems have been observed during late embryonic development (Decuypere et al., 2005). Julian (1989) reported that insufficient lung volume, or oxygen exchange area, in meattype chickens leads to ascites. Broiler embryos incubated at high altitude hatch early, have higher $\mathrm{T}_{3}, \mathrm{~T}_{4}$, corticosterone and embryonic mortality but lower incidence of ascites at high altitude compared to those incubated at low altitude and transported to high altitude (Hasssanzadeh et al., 2004). This suggests that the incidence of ascites is not only related to oxygen insufficiency at high altitude but can be alleviated by acclimation of the embryos to oxygen insufficiency during incubation.

When incubated under normal conditions, ascites sensitive lines show lower metabolism, lower thyroid activity at the end of incubation and lower embryonic body weight early in incubation compared to ascites resistant lines (Dewil et al., 1996; De Smit et al., 2005) suggesting that $21 \% \mathrm{O}_{2}$ may not be sufficient for ascites sensitive lines of broilers. This agrees with the findings reported for the Leghorn egg type lines. This suggests that more studies are required to establish the requirements of the different lines of chickens especially in view of recent studies that have shown that metabolic rates differ between the embryos of layers and broilers and also between different lines of broilers (Janke et al., 2004; Tona et al., 2004; De Smit et al., 2005; Chwalibog et al., 2006).

\section{The role of carbon dioxide}

The advent of large capacity incubators has made the storage of eggs before incubation a necessity in order to make up the numbers that are required to fill the incubators. Storage of eggs before incubation has consequences on the quality of the eggs and their hatchability. At lay, the egg contains a copious amount of bicarbonate and $\mathrm{CO}_{2}$ stored in the albumen (Healy and Peter, 1925; Brook and Pace, 1938).

The $\mathrm{pH}$ of the albumen has variously been recorded to range from 7.6 to 8.2 at lay but increases to about 9.2-9.7 after storage in air (Becket et al., 1968; Tona et al., 2001). This indicates that the egg loses $\mathrm{CO}_{2}$ during storage (Smith, 1933) and this has been shown to 


\section{Role of gaseous exchange in egg storage and incubation: O. Onagbesan et al.}

alter the Haugh units (a measure of the internal quality of the albumen). Paradoxically, the egg must lose some of the $\mathrm{CO}_{2}$ to improve its hatchability but the loss must come at the right time. Decuypere et al. (2001) stated that excessive loss of $\mathrm{CO}_{2}$ leads to high albumen $\mathrm{pH}$ and may have a negative effect on the initiation of embryo development.

Gillespie and McHanwell (1987) showed that optimum gastrulation occurs at $\mathrm{pH}$ 8.2. Thus the alkalinity of the albumen needs to be preserved. A few reports have shown that the supply of $\mathrm{CO}_{2}$ during incubation may be beneficial to the growth of embryos and the hatchability of eggs. In nature, hypercapnia is common occurrence under the incubating hen (Walsberg, 1980) suggesting that $\mathrm{CO}_{2}$ may have a role in incubation.

\section{CARBON DIOXIDE REQUIREMENT AND ITS EFFECTS DURING PRE- INCUBATION PERIOD}

During the pre-incubation period, hatching eggs must be stored such that it retains its original $\mathrm{pH}$, appropriate $\mathrm{CO}_{2}$ content in the albumen and Haugh Units to maintain good quality before setting for incubation. Thus storage must ensure inexcessive loss of $\mathrm{CO}_{2}$ from the egg. Cotterill et al. (1958) concluded that the total amount of $\mathrm{CO}_{2}$ given off during storage is a function of the partial pressure of $\mathrm{CO}_{2}$ in the atmosphere. Smith et al. (1931) demonstrated that in order to maintain the $\mathrm{pH}$ of egg albumen near its original value at lay, the storage atmosphere should contain $2-3 \% \mathrm{CO}_{2}$ at $32^{\circ} \mathrm{F}$ and $3-4.5 \% \mathrm{CO}_{2}$ at room temperature. Thus Swanson et al. (1954), Cotterill et al. (1957), Fletcher et al. (1959) and Becker et al. (1968) showed that storing eggs in moisture proof packages in a $\mathrm{CO}_{2}$ atmosphere reduced the loss of albumen quality and maintained $\mathrm{pH}$ at the level of fresh eggs.

The presence of ambient $\mathrm{CO}_{2}$ during storage decreases the rate of $\mathrm{CO}_{2}$ loss such that the total amount lost is minimized over a given period of storage depending on the environmental temperature. Romanoff (1960) reported that an increase in albumen $\mathrm{pH}$ is associated with a decrease in albumen quality and an increase in early embryonic mortality. An increase in early embryonic mortality has also been associated with good albumen quality in eggs incubated without storage (Brake et al., 1993).

Meuer and Baumann (1988) reported that the albumen of a fresh egg presents great resistance to gaseous diffusion during early incubation and ultimately lead to embryonic mortality. Walsh et al. (1995) reported that eggs stored in $\mathrm{CO}_{2}$ environment for 7 days exhibited higher albumen height but higher embryonic mortality than the controls whereas those stored for 14 days also had higher albumen height and lower $\mathrm{pH}$ but lower embryonic mortality than the controls during incubation. Becker et al. (1964) recorded higher hatchability results in chicken eggs stored in $\mathrm{CO}_{2}$ for 8-15 days compared to the controls.

Sauveur et al. (1967) reported three times higher hatchability of the eggs of a broiler type chicken when eggs were stored in $2 \% \mathrm{CO}_{2}$ atmosphere for 3 weeks and that hatchability decreased as the duration of storage decreased. The reports of Sauveur et al. (1967) and Walsh et al. (1995) stressed a greater benefit of storage in $\mathrm{CO}_{2}$ for eggs from older breeder hens than those for young breeder hens, probably because of the higher conductivity of shells of older breeders, hence a quicker loss of $\mathrm{CO}_{2}$.

\section{CARBON DIOXIDE REQUIREMENT AND ITS EFFECTS DURING INCUBATION PERIOD}

During incubation, $\mathrm{CO}_{2}$ is released by eggs, first from the natural reservoir in the albumen, combined with the limited metabolic production by the early embryo, and later as the metabolic byproduct of the developing embryo and limited release by the albumen. Burke (1925) reported that in the naturally incubating hen, the $\mathrm{CO}_{2}$ in the air around the clutch of chicken eggs increased from $0.05 \%$ to $0.9 \%$ by the end of incubation. Freeman 


\section{Role of gaseous exchange in egg storage and incubation: O. Onagbesan et al.}

and Vince (1974) also showed that as incubation progresses, the embryo produces several times the $\mathrm{CO}_{2}$ produced during earlier stages of development.

Lundy (1969), Taylor and Kreutziger (1965, 1966, 1969), Taylor et al. (1971) have shown that chicken embryos become less sensitive to elevated nest or incubator $\mathrm{CO}_{2}$ concentrations with increasing age. Although higher incubator $\mathrm{CO}_{2}$ levels have previously been regarded as detrimental to embryo development, recent reports have shown that hypercapnia may be beneficial to the developing embryo depending on the timing of its occurrence. In practice, $\mathrm{CO}_{2}$ levels in the range of $0.1-0.5 \%$ are used during incubation of poultry eggs. Recent research studies have shown that higher levels change the course of embryo development and the hatchability of the eggs.

\section{Effects on hatching process and hatchability}

The early studies of Taylor et al. (1956), Taylor and Kreutziger $(1965,1966)$ showed that $\mathrm{CO}_{2}$ concentrations more than $1 \%$ during the first 4 days of incubation, $3 \%$ from 3 to 5 days of incubation, $6 \%$ between 9 and 12 days, $8 \%$ during d 13 - d16 or more than $7 \%$ from d 17 to d 20 of incubation depressed hatchability. The presence of $\mathrm{CO}_{2}$ levels higher than 6-7\% has been shown to decrease $\mathrm{O}_{2}$ levels in the incubator significantly and exacerbates the detrimental effects of these high $\mathrm{CO}_{2}$ levels (Taylor and Kreutziger, 1989; Taylor et al., 1971). However, in the second half of the incubation period, the restoration of $\mathrm{O}_{2}$ levels to normoxic levels in the presence of high $\mathrm{CO}_{2}$ has been reported to restore optimum hatchability while restoration to hyperoxic levels caused an increase in hatchability compared with control incubations (Taylor and Kreutziger, 1969). This suggests a synergistic effect of $\mathrm{CO}_{2}$ and $\mathrm{O}_{2}$ at high levels which may be of benefit to the developing embryo. Romanoff and Romanoff (1933), Barrott (1937) also reported negative impact on the hatchability of chicken eggs when incubator $\mathrm{CO}_{2}$ levels exceeded $1 \%$ during very early incubation.

More recent studies have shown that a gradual increase in $\mathrm{CO}_{2}$ levels up to $1.5 \%$ in the first 10 days of incubation enhanced embryo growth, stimulated early hatching and increased hatchability of chicken or turkey eggs (Gildersleeve and Boeschen, 1983; Hogg, 1997; De Smit et al., 2006; Tona et al., 2006). Saddler et al. (1954) reported that $4 \% \mathrm{CO}_{2}$ stimulated embryo growth by as much as $20 \%$ in the first 48 hours of incubation. Haring et al. (1970) also recorded a 10\% increase in embryo body weight when eggs were incubated for just $24 \mathrm{~h}$ on any one day in the first $10 \mathrm{~d}$ of incubation under a $\mathrm{CO}_{2}$ level that has been shown to be teratogenic (6\%). In the experiment, however, high embryo mortality was recorded.

Bruggeman et al. (2006) have also recently reported that hypercapnic embryos hatched earlier when $\mathrm{CO}_{2}$ level in the incubator was increased to $1.5 \%$ at the 96th hr of incubation and maintained at that level until the 10th day of incubation. De Smit et al. (2007) demonstrated that increasing the incubator $\mathrm{CO}_{2}$ level to $0.7 \%$ during the first 10 days of incubation accelerates the hatching process in ascites resistant as well as in ascites sensitive broiler lines. Everaert et al. (2007) found that exposure of the embryos to high $\mathrm{CO}_{2}(4 \%)$ during the second half of the incubation period $(\mathrm{d} 10-\mathrm{d} 18)$ had no effect on hatchability or hatching time but increased embryo weights. These studies indicate clearly that the sensitivity of the chick embryo to environmental $\mathrm{CO}_{2}$ changes with age as it does with $\mathrm{O}_{2}$.

\section{Embryo buffering and sub-embryonic fluid}

The role of incubation $\mathrm{CO}_{2}$ during early incubation has been shown to influence the rapid acidification of the albumen, liquefaction of the albumen and the formation of the sub-embryonic fluid (Benton and Brake, 1996; Bruggeman et al., 2006). As $\mathrm{CO}_{2}$ is highly soluble in egg albumen (Visschedijk, 1968), protons and bicarbonates are rapidly formed 


\section{Role of gaseous exchange in egg storage and incubation: O. Onagbesan et al.}

for albumen buffering effects around the developing embryo. The early liquefaction of the albumen also facilitates the movement of various nutrients from the albumen towards the embryo (Burley and Vadehra, 1989) and also reduces any physical barrier to $\mathrm{O}_{2}$ diffusion to the embryo (Meuer and Baumann, 1988).

Latter and Baggott (2002) have demonstrated in vitro using quail embryos that $\mathrm{CO}_{2}$ has a role in the formation of the sub-embryonic fluid (SEF) during early incubation. Deeming (1989) reported that the formation of the SEF has a pivotal role in the survival of the embryo. De Smit et al. (2006) have argued that with the early and enhanced occurrence of these processes in the presence of higher $\mathrm{CO}_{2}$ environment, embryonic development is enhanced and thus explains the higher body weights recorded for embryos under tolerable hypercapnic conditions during early incubation (De Smit et al., 2006; Tona et al., 2006; Saddler et al., 1954).

Meuer et al. (1989) reported that exposure to high $\mathrm{CO}_{2}(3 \%)$ can lead to decreases in blood and tissue $\mathrm{pH}$ of the embryo which may impact on cellular processes. Dawes and Simkiss $(1969,1971)$, Boutilier et al. (1977) have shown that the chick embryo is capable of maintaining blood $\mathrm{pH}$ with little changes when incubated under hypercapnic conditions either in the first half or the second half of incubation periods. $\mathrm{CO}_{2}$ levels up to $9 \% \mathrm{CO}_{2}$ did not affect acid/base balance in the blood during the 12th-17th day of incubation (Dawes and Simkiss, 1971). This has been shown to be due to the capacity of the embryo to generate or increase bicarbonate from shell reabsorption or renal/allantoic compensations.

In recent studies, Everaert et al. (2007) affirmed that the chick embryo has several adaptive mechanisms for coping with high environmental $\mathrm{CO}_{2}$ during the second half of the incubation period. They observed that blood $\mathrm{pCO}_{2}$ did not differ between the control embryos and those exposed to incubator $\mathrm{CO}_{2}$ level of $4 \%$ between the 10th and 18th day of incubation. Blood bicarbonate concentration was higher in the high $\mathrm{CO}_{2}$ group but was not accompanied by a more acid $\mathrm{pH}$ suggesting that protons were taken up from the blood and were buffered elsewhere. The buffering caused a temporary increase in blood calcium suggesting a reaction of the protons with calcium carbonate from the shell. There was also an increase in potassium suggesting an exchange of $\mathrm{H}^{+}$with $\mathrm{K}^{+}$at the cellular level. The authors did not observe an increase in allantoic fluid acidity or ammonia level suggesting that renal contribution for buffering at this stage may be minor.

Bruggeman et al. (2006) measured albumen $\mathrm{pH}, \mathrm{CAM}$ weight, air cell $\mathrm{pCO}_{2}$, blood $\mathrm{pCO}_{2}$ and bicarbonates in a $\mathrm{CO}_{2}$-controlled incubator that increased $\mathrm{CO}_{2}$ gradually between 25th and 96th hour to reach $1.5 \%$ at 96 hours and continued incubation until day 10 at $1.5 \%$. The authors observed no difference in CAM weight compared with control incubation. However, albumen $\mathrm{pH}$, air cell $\mathrm{pCO}_{2}$, blood $\mathrm{pCO}_{2}$ and bicarbonates were higher in hypercapnic embryos but blood $\mathrm{pH}$ was not different. The study suggests that $\mathrm{CO}_{2}$ levels of $1.5 \%$ are tolerable to the chick embryo beyond 96 th hour of incubation. Thus the increasing tolerance of the embryo to $\mathrm{CO}_{2}$ during incubation may be ascribed partly to the several buffering mechanisms.

\section{Embryo growth}

Studies on the hypercapnic effects $(0.4 \%$ at d14-d19) during the second half of incubation have shown that $\mathrm{CO}_{2}$ also increased embryonic weight, reduced the incidence of ascites, initiated early hatch and increased chick hatching weight but some of these effects were more obvious in an ascites sensitive line of broilers than in an ascites resistant line (Buys et al., 1998). De Smit et al. (2007) observed increased embryonic growth in broiler lines selected for ascites sensitivity or ascites resistance when eggs were incubated under $0.7 \% \mathrm{CO}_{2}$. Other reports have also confirmed the growth promoting effect of increased incubator $\mathrm{CO}_{2}$ level either during early incubation or during the second half of 


\section{Role of gaseous exchange in egg storage and incubation: O. Onagbesan et al.}

incubation (Saddler et al. 1954; Haring et al. 1970; De Smit et al., 2006; Tona et al., 2006; Everaert et al. 2007).

Post-hatch growth of chicks that hatch from eggs that were incubated under higher $\mathrm{CO}_{2}$ levels $(1.5 \%)$ has been reported to be higher during the first two weeks of rearing compared to those from control incubation (De Smit et al. 2006). In another study, De Smit et al. (2007) observed higher post hatch growth in ascites resistant and ascites sensitive lines that were incubated under higher $\mathrm{CO}_{2}$ levels $(0.7 \%)$ during embryonic development. At slaughter age, both lines had higher body weights but when exposed to stressful conditions they showed higher incidence of ascites and mortality.

\section{Metabolic effects, organ development and embryo mortality}

A decrease in hatchability often results from high embryonic mortality or morphological /physiological abnormalities in the presence of high $\mathrm{CO}_{2}$ depending on the timing of application. The implications of higher $\mathrm{CO}_{2}$ level on morphological/physiological aspects of development have not been studied in depth. It can only be speculated that the effect of $\mathrm{CO}_{2}$ must have been an inhibition of those parameters that enhance embryonic survival.

Saddler et al. (1954) reported that $\mathrm{CO}_{2}$ enhanced amnion closure during early incubation but high levels beyond $1 \%$ retarded its closure at a specific window of the 4872 hours of incubation. The authors concluded that although the chick embryo is tolerant to high $\mathrm{CO}_{2}$ up to $4 \%$ during the first ten days, relatively low tolerance periods may exist between the 2 nd and 10th day of incubation. They established that $0.9 \%$ seems to be the highest tolerance level at these sensitive periods. Haring et al. (1970) reported that the high level of embryonic mortality after exposure to $6 \% \mathrm{CO}_{2}$ for 24 hours at any time during the first $10 \mathrm{~d}$ of incubation resulted from non-cardiac and cardiac malformations.

Incubation under hypercapnic conditions during the last half of incubation has also been reported to influence hatching process (Buys et al., 1998) and the morphological and physiological parameters of the embryo (Mortola, 2004; Gonya and Stoke, 1998; Dawes and Simkiss, 1991; Buys et al., 1998). Buys et al. (1998) associated early hatching in hypercapnic embryos with increases in plasma $\mathrm{T}_{3}$ levels at day 20 of incubation. De Smit et al. (2006) and Tona et al. (2006) also reported increased $\mathrm{T}_{3}$ and higher $\mathrm{pCO}_{2}$ in the air cell at day 20 when embryos were incubated under hypercapnic conditions early in incubation.

Dawes (1975), Menna and Mortola (2003) and Mortola (2004) reported that short-term hypercapnia affects lung function during the transition to pulmonary ventilation at external pipping. The authors demonstrated the stimulatory effect of $\mathrm{CO}_{2}$ on the chemoreceptors that enhance breathing efficiency and that hyperoxia at this period diminishes the effect of hypercapnia. Thus hypercapnia can achieve a similar effect as hypoxia on lung function during pipping and hatching.

Decuypere et al. (1991) and Visschedijk (1968) have linked the level of blood $\mathrm{T}_{3}$, air cell $\mathrm{pCO}_{2}$ to the process of early hatching. Thus the positive effects of hypercapnic incubation suggest an augmentation of $\mathrm{T}_{3}$ and air cell $\mathrm{pCO}_{2}$ to effect early hatch and enhanced hatchability. Visschedijk (1968b) demonstrated that covering the air space to increase $\mathrm{pCO}_{2}$ accelerates pipping. However, more studies are required to establish the limit of beneficial levels.

Gonya and Stokes (1978) showed that progressive hypercapnia during the 14th-19th day of incubation is associated with a gradual decline in motor activity in the spinal cord with an effect on limb muscles of the chick embryo. 
Role of gaseous exchange in egg storage and incubation: O. Onagbesan et al.

\section{Conclusion}

Taken together, these reports suggest that hypoxia at any level below $15 \%$, no matter when applied but more especially during early development, alters the developmental profile of the embryonic chicken which may compromise the survivability of the chick, thus lowering hatchability. If the chick survives until hatch, it might be disposed to cardiovascular diseases as often seen in ascites chickens. There are indications however, that hypoxia during the pipping period may be beneficial for early hatching.

From hatchery management point of view, higher $\mathrm{O}_{2}$ levels than are currently used at mid incubation period may be of benefit for embryo development and hatchability since any detrimental effects are not apparent below the 50\% level. Taylor and Kreutziger (1966) actually reported higher hatchability than the control $\left(21 \% \mathrm{O}_{2}\right)$ in 8 of 9 experiments with $\mathrm{O}_{2}$ above $21 \%$ at day 4-8 suggesting the possibility of increasing hatchability depending on the metabolic rate of the embryo.

With regards to the roles of $\mathrm{CO}_{2}$, it would seem that the chicken embryo requires $\mathrm{CO}_{2}$ at specific windows of development to enhance growth, early hatch and optimum hatchability. $\mathrm{CO}_{2}$ tends to achieve similar effects as hypoxia as it also promotes the development and functioning of certain embryonic organs. Thus it could be substituted for $\mathrm{O}_{2}$ at the effective level. For example, as hypoxia is detrimental at early incubation but has been reported to enhance CAM development, increasing the level of $\mathrm{CO}_{2}$ at this time period may be practiced without detrimental effects on embryo development. And for the purpose of stimulating early hatch and shortening incubation period, $\mathrm{CO}_{2}$ seems to achieve this when applied at the appropriate level early or late in incubation.

Further fine tuning and determining the critical windows for hypercapnia as well as for hypoxia or hyperoxia, and the optimal levels of $\mathrm{CO}_{2}$ and $\mathrm{O}_{2}$ during other periods seem to be a challenge for further research. These studies are also necessary for optimizing the gaseous conditions for practical incubation in order to obtain the best chick quality for later performance and robustness. These conditions may vary as a function of what is determined as best chick quality with respect to the strains of the chicks and the rearing conditions.

\section{Acknowledgement}

V. Bruggeman is a postdoctoral fellow of the FWO-Vlaanderen, Belgium. L. De Smit is supported by the Fund for Scientific Research Flanders (F.W.O. Vlaanderen, Belgium). Annouk Witters is supported by IWT, Belgium.

\section{References}

ALTIMIRAS, J. and PHU, L. (2000) Lack of physiological plasticity in the early chicken embryo exposed to acute hypoxia. Journal of Experimental Zoology 286: 450-456.

AR. A., PAGANELLI, C.V., REEVES, R.B., GREENE, D.G. and RAHN, H. (1974) The avian egg: water vapor conductance, shell thickness and functional pore area. The Condor 76: 153 - 158.

ASSON-BATRES, M.A., STOCK, M.K., HARE, J.F. and METCALFE, J. (1989) O2 effect on composition of chick embryonic heart and brain. Respiratory Physiology 77: 101-109.

BAMELIS, F.R., TONA, K., DE BAERDEMAEKER, J. and DECUYPERE, E. (2001) Increasing chicken eggs hatchability by matching incubator humidity to eggshell conductance. Proceedings Incubation and Fertility Research Group, Oxford, UK; 11 - 12 Sept. 2001. International Hatchery Practice 16 (3): 24.

BAMELIS, F.R. (2003) Non-invasive assessment of eggshell conductance at different developmental stages during incubation of eggs. PhD thesis, Catholic University, Leuven, Belgium.

BARROT, H.G. (1937) Effect of temperature, humidity, and other factors on hatch of hens' eggs and on energy metabolism of chick embryos. USDA Technical Bulletin 553: 1-45. 


\section{Role of gaseous exchange in egg storage and incubation: O. Onagbesan et al.}

BAUMANN, R., PADEKEN, S., HALLER, E.A. and BRILMAYER, T. (1983) Effects of hypoxia on oxygen affinity, haemoglobin pattern, and blood volume of early chicken embryos. American Physiology 244: R733R741.

BECKER, W.A. (1964) The storage of White Leghorn hatching eggs in plastic bags. Poultry Science 43: 11091112.

BECKER, W.A., SPENCER, J.V. and SWARTWOOD, J.L. (1964) The pre-incubation storage of turkey eggs in closed environments. Poultry Science 43: 1526-1534.

BECKER, W.A., SPENCER, J.V. and SWARTWOOD, J.L. (1968) Carbon dioxide during storage of chicken and turkey hatching eggs. Poultry Science 47: 251-258.

BENTON, C.E. and BRAKE, J. (1996) The effect of broiler breeder flock age and length of storage on egg albumen during early incubation. Poultry Science 75: 1069-1075.

BLACKER, H.A., ORGEIG, S. and DANIELS, C.B. (2004) Hypoxic control of the development of the surfactant system in the chicken: evidence for physiological heterokairy. American Journal of Physiology Regulatory Integrative and Comparative Physiology 287: 403-410.

BOSE, S. and STEWART, G.F. (1948) Comparative and complementary effects of heat treating and oiling shell eggs on their keeping quality. Poultry Science 27: 228-234.

BOUTILIER, R.G., GIBSON, M.A., TOEWS, D.P. and ANDERSON, W. (1977) Gas exchanges and acidbase regulation in the blood and extraembryonic fluids of the developing chicken embryo. Respiration Physiology 31: 81-89.

BRAKE, J., WALSH, T.J. and VICK, S.V. (1993) Relationship of egg storage time, storage conditions, flock age, eggshell and albumen characteristics, incubation conditions, and machine capacity to broiler hatchabilityReview and model synthesis. Zootechnical International 16: 30-41.

BROOKS, J. and PACE, J. (1938) The distribution of carbon dioxide in the hen's egg. Proceedings of Royal Society London, series B, Biological Sciences 126: 196-210.

BRUGGEMAN, V., WITTERS, A., DE SMIT, L., DEBONNE, M., EVERAERT, N., KAMERS, B., ONAGBESAN, O.M., DEGRAEVES, P. and DECUYPERE, E. (2006) Changes in parameters related to acid-base balance in chicken embryos (Gallus domesticus) incubated under normal or high $\mathrm{CO} 2$ concentrations during the first ten days of incubation. Respiratory Physiology and Neurobiology (in press).

BURKE, E. (1925) A study of incubation. Bulletin of University of Montana Agricultural Experimental Station 178: $1-43$

BURLEY, R.W. and VADEHRA, D.V. (1989) The avian egg: Chemistry and Biology. John Wiley and Sons, NY.

BURTON, G.F., STEVENSON, J.M. and TULLETT, S.G. (1989) The relationship between eggshell porosity and air space gas tensions measured before and during the parafoetal period and their effects on the hatching process in the domestic fowl. Respiration Physiology 77: 89-100.

BURTON, G.J. and PALMER, M.E. (1992) Development of the chick chorioallantoic capillary plexus under normoxic and normobaric hypoxic and hyperoxic conditions: a morphometric study. Journal of Experimental Zoology 262: 291-298.

BURTON, F.G. and TULLETT, S.G. (1983) A comparison of the effects of eggshell porosity on the respiration and growth of domestic fowl, duck and turkey embryos. Comparative Biochemistry and Physiology 75A: 167174.

BUYS, N., DEWIL, E., GONZALES, E. and DECUYPERE, E. (1998) Different CO2 levels during incubation interact with hatching time and ascites susceptibility in two broiler lines selected for different growth rate. Avian Pathology 27: 605-612.

CHAN, T. and BURGGREN, W. (2005) Hypoxic incubation creates differential morphological effects during specific developmental critical windows in the embryo of the chicken (Gallus gallus). Respiratory Physiology and Neurobiology 145: 251-263.

CHWALIBOG, A., TAUSON, A-H., ALI, A., MATTHIESEN, C., THORHAUGE, K. and THORBEK, G. (2006) Gas exchange, heat production and oxidation of fat in chicken embryos from fast or slow growing line. Comparative Biochemistry and Physiology A (doi: 10.1016/j.cbpa.2006.10.035).

COTTERILL, O.J. and GARDNER, F. (1957) Retarding thick white deterioration by holding shell eggs in sealed containers. Poultry Science 34: 196-206.

COTTERILL, O.J., GARDNER, F.A., FUNK, E.M. and CUNNINGHAM, F.E. (1958) Relationship between temperature and carbon dioxide loss from shell eggs. Poultry Science 37: 479-483.

CROSSLEY II, D.A., BURGGREN, W.W. and ALTIMIRAS, J. (2003) Cardiovascular regulation during hypoxia in embryos of the domestic chicken, Gallus gallus. American Journal of Physiology Regulatory Integrative and Comparative Physiology 284: 219-226.

CRUZ, S.R. and ROMANOFF, A.L. (1944) Effect of oxygen concentration on the development of the chick embryo. Physiological Zoology 17: 184-187.

DAWES, C.M. (1975) Acid-base relationships within the avian egg. Biological Review 50: 351-371.

DAWES, C.M. and SIMKISS, K. (1969) The acid base status of the blood of the developing chick embryo. Journal of Experimental Biology 50: 79-86. 


\section{Role of gaseous exchange in egg storage and incubation: O. Onagbesan et al.}

DAWES, C.M. and SIMKISS, K. (1971) The effects of respiratory acidosis in the chick embryo. Journal of Experimental Biology 55: 77-84.

DE SMIT, L., BRUGGEMAN, V., DEBONNE, M., TONA, K., ONAGBESAN, O., ARCKENS, L., DE BAERDEMAEKER, J. and DECUYPERE, E. (2007) The effects of non-ventillation during early incubation on the development of chick embryos of two commercial broiler strains. British Poultry Science (submitted for publication).

DE SMIT, L., BRUGGEMAN, V., DEBONNE, M., TONA, K., ONAGBESAN, O., ARCKENS, L., DE BAERDEMAEKER, J. and DECUYPERE, E. (2007) The effects of non-ventillation during early incubation on posthatch performance and ascites susceptibility of two commercial broiler strains. Avian Pathology (submitted for publication).

DE SMIT, L., BRUGGEMAN, V., TONA, K., DEBONNE, M., ONAGBESAN, O., ARCKENS, L., DE BAERDEMAEKER, J. and DECUYPERE, E. (2006) Embryonic developmental plasticity of the chick: increased $\mathrm{CO} 2$ during early stages of incubation changes the developmental trajectories during prenatal and postnatal growth. Comparative Biochemistry and Physiology A. Molecular and Integrative Physiology 145: 166-175.

DE SMIT, L., TONA, K., BRUGGEMAN, V., ONAGBESAN, O., HASSANZADEH, M., ARKENS, L. and DECUYPERE, E. (2005) Comparison of three lines of broilers differing in ascites susceptibility or growth rate. 2. Egg weight loss, gas pressures, embryonic heat production, and physiological hormone levels. Poultry Science 84: 1446-1452.

DECUYPERE, E., DEWIL, E. and KUHN, E.R. (1991) The hatching process and the role of hormones. In: Avian Incubation. Ed. S.G. Tullett. Butterworth-Heinemann, London.

DECUYPERE, E., HASSANZADEH, E., BUYS, N. and BUYSE, J. (2005) Further insights into the susceptibility of broilers to ascites. Veterinary Journal 169: 319-320.

DEEMING, D.C. (1989) Importance of sub-embryonic fluid and albumen in the embryo's response to turning of the egg during incubation. British Poultry Science 30: 591-606.

DEWIL, E., BUYS, N., ALBERS, G.A.A. and DECUYPERE, E. (1996) Different characteristics in chick embryos of two broiler lines differing in susceptibility to ascites. British Poultry Science 37: 1003-1013.

DIETZ, M.W., VANKAMPEN, M., VANGRIESVEN, M.J.M. and VANMOURIK, S. (1998) Daily energy budgets of avian embryos: The paradox of the plateau phase in egg metabolic rate. Physiological Zoology 71: 147-156.

DUSSEAU, J.W. AND HUTCHINS, P.M. (1988) Hypoxia-induced angiogenesis in chick chorioallantoic membranes: a role for adenosine. Respiration Physiology 71: 33-44.

DUNKER, H.R. (1978) Development of the avian respiratory and circulatory systems. In: Respiratory functions in birds, adult and embryonic (Ed. J. Piiper), pp. 260-273. Springer-Verlag, Berlin.

DZIALOWSKI, E., VON PLETTENBERG, D., ELMONOUFY, N.A. and BURGGREN, W.W. (2002) Chronic hypoxia alters the physiological and morphological trajectories of developing chicken embryos. Comparative Biochemistry and Physiology A Molecular and Integrative Physiology 131: 713-724.

EL-IBIARY, H.M., SHAFFNER, C.S. and GODFREY, E.F. (1966) Pulmonary ventilation in a population of hatching chick embryos. British Poultry Science 7: 165-176.

EVERAERT, N., DEBONNE, M., WITTERS, A., DE SMIT, L., KAMERS, B., DECUYPERE, E., BRUGGEMAN, V. (2007) Changes in acid-base balance and related physiological responses as a result of external hypercapnia during the second half of incubation in the chicken embryo. Poultry Science (in press).

FLETCHER, D.A., ORR, H.L., SNYDER, E.S. and NICHOLSON, A.O. (1959) Effect of oiling, packaging materials and addition of $\mathrm{CO} 2$ on quality of shell eggs held in storage. Poultry Science 38: 106-111.

FREEMAN, B.M., VINCE, M.A. (1974) Development of the avian embryo. Chapman and Hall. London.

GEFEN, E and AR, A. (2001) Gas exchange and energy metabolism of the ostrich (Struthio camelus) embryo. Comparative Biochemistry and Physiology A Molecular and Integrative Physiology 130: 689-699.

GILDERSLEEVE, R.P. and BOESCHEN, D.P. (1983) The effect of incubator carbon dioxide on turkey hatchability. Poultry Science 62: 779-784.

GILLESPIE, J.I. and MCHANWELL, S. (1987) Measurements of intra embryonic pH during early stages of development in the chick embryo. Cell Tissue Research 247: 445-451.

GODWIN, T.L., WILSON, M.L. and STADELMAN, W.J. (1962) The effects of oiling, storage position and storage time on the condition of shell eggs. Poultry Science 41: 840-844.

GONYA, T. and STOKES, B.T. (1978) A neurophysiological analysis of the effects of hypercapnia on the embryonic spinal cord. Developmeantal Neuroscience 1: 164-171.

HAMILTON, R.M.G. (1978) Observations on the changes in physical characteristics that influence egg shell quality in ten strains of white leghorns. Poultry Science 57: 1192-1197.

HARING, O.H., PATTERSON, J.R. and SARCHE, M.A. (1970) Prenatal development of the cardiovascular system in the chicken. Archives of Pathology 89: 537-547.

HASSANZADEH, M., BUYSE, J. and DECUYPERE, E. (2002) Further evidence for the involvement of cardiac B-adrenergic receptors in right ventricle hypertrophy and ascites in broiler chickens. Avian Pathology 31: $177-181$. 
Role of gaseous exchange in egg storage and incubation: O. Onagbesan et al.

HASSANZADEH, M., FARD, M.H.B., BUYSE, J., BRUGGEMAN, V. and DECUYPERE, E. (2004) Effect of chronic hypoxia during embryonic development on physiological functioning and on hatching and posthatching parameters related to ascites syndrome in broiler chickens. Avian Pathology 33: 558-564.

HOGG, A. (1997) Single stage incubation trials. Poultry and Avian Biology Review 8: 168.

HOPER, J. and HAHN, H. (1995) Influence of environmental oxygen concentration on growth and vascular density of the vasculosa in the chick embryos. International Journal of Microcirculation and Clinical Experimentation 15: 186-192.

HURWITZ, S. (1987) Effect of nutrition on egg quality. In: Egg quality - Current problems and recent advances. Ed. R.G. Wells and C.G. Belyavin. Butterworths, London.

JANKE, O., TZSCHENTKE, B. and BOERJAN, M.L. (2004) Comparative investigation of heat production and body temperature in embryos of modern chicken breeds. Avian and Poultry Biology Reviews 15: 191-196.

JULIAN, R.J. (1989) Lung volume of meat type chickens. Avian Diseases 33: 174-176.

JULIAN, R.J. (1993) Ascites in poultry. Avian Pathology 22: 419-545.

JULIAN, R.J. (2000) Physiological management and environmental triggers of the ascites syndrome: a review. Avian Pathology 29: 519-527.

KIRK, S., EMMANS, G.C., MCDONALD, R. and ARNOT, D. (1980) Factors affecting the hatchability of eggs from broiler breeders. British Poultry Science 21: 37-53.

LATTER, G.V. and BAGGOTT, G.K. (2002) Role of carbon dioxide and ion transport in the formation of subembryonic fluid by the blastoderm of the Japanese quail. British Poultry Science 43: 104-116.

LUNDY, H. (1969) A review of the effects of temperature, humidity, turning and gaseous environment in the incubator on the hatchability of the hen's egg. In: Fertility and Hatchability of the hen's egg. Ed: T.C. Carter and B.M. Freeman. Liver and Beard, Edinburgh. Pp 143-176.

MATHER, C.M. and LAUGHLIN, K.F. (1976) Storage of hatching eggs: the effect on total incubation period. British Poultry Science 17: 471-479.

MATHER, C.M. and LAUGHLIN, K.F. (1979) Storage of hatching eggs: the interaction between parental age and early embryonic development. British Poultry Science 20: 595-604.

MCCUTCHEON, I.E., METCALFE, J., METZENBERG, A.B. and ETTINGER, T. (1982) Organ growth in hyperoxic and hypoxic chick embryos. Respiratory Physiology 50: 153-163.

MCDANIEL, G.R., ROLAND, D.A. and COLEMAN, M.A. (1979) The effect of egg shell quality on hatchability and embryonic mortality. Poultry Science 58: 10-13.

MENNA, T.M. and MORTOLA, J.P. (2003) Ventilatory chemosensitivity in the chick embryo. Respiratory Physiology and Neurobiology 137: 69-79.

MEUER, H.J. and BAUMANN, R. (1988) Oxygen pressure in intra- and extra-embryonic blood vessels of early chick embryos. Respiration Physiology 71: 331-342.

MEUER, H.J., SIEGER, U. and BAUMANN, R. (1989) Measurement of pH in blood vessels and interstitium of 4 and 6 days old chick embryos. Journal of Developmental Physiology 11: 354-359.

MORTOLA, J.P. (2004) Ventilatory response to hypoxia in the chick embryo. Comparative Biochemistry and Physiology A. Molecular Integrative Physiology 137: 723-730.

PAGANELLI, C.V., SOTHERLAND, P.R., OLSZOWKA, A. and RAHN, H. (1988) Regional differences in diffusive conductance/perfusion ratio in the shell of the hen's egg. Respiration Physiology 71: 45-56.

PEACOCK, A.J., PICKETT, C., MORRIS, K. and REEVES, J.T. (1990) Spontaneous hypoxemia and right ventricular hypertrophy in fast growing broiler chickens reared at sea level. Comparative Biochemistry and Physiology A Molecular Integrative Physiology 97: 537-547.

PEEBLES, E.D. and BRAKE, J. (1987) Eggshell quality and hatchability in broiler breeder eggs. Poultry Science 66: 596-604.

PROUDFOOT, F.G. (1964) The effects of plastic packaging and other treatments on hatching eggs. Canadian Journal of Animal Science 44: 87-95.

PROUDFOOT, F.G. (1965) The effect of film permeability and concentration of nitrogen, oxygen and helium gases on hatching eggs stored in polyethylene and Cryovac bags. Poultry Science 44: 636-644.

RAHN, R. (1981) Gas exchange of avian eggs with special reference to turkey eggs. Poultry Science 60: 19711980.

RAHN, H. and AR, A. (1980) Gas exchange of the avian egg: time, structure and function. American Zoology 20: $477-484$.

RAHN, H., CHRISTENSEN, V.L. and EDENS, F.W. (1981) Changes in shell conductance, pores and physical dimensions of egg and shell during the first breeding cycle of the turkey hens. Poultry Science 60: 2536-2541.

REIZIS, A., HAMMEL, I. and AR, A. (2005) Regional and developmental variations of blood vessels morphometry in the chick embryo chorioallatoic membrane. Journal of Experimental Biology 208: 24832488.

REMOTTI, E. (1933) Adattamento respiratorio e suo substrato morfologico nello sviluppo embrionale degli Uccelli. Boll. Mus. Zool. E Anat. Comp. R. Univ. Genova. Ser. II. 13, 3-21.

RICHARDS, M.P., STOCK, M.K. and METCALFE, J. (1991) Effects of brief hypoxia and hyperoxia on tissue trace element levels in the developing chick embryo. Magnesium Trace Element 10: 305-320.

RIDDLE, O. (1924) On the necessary gaseous environment of the bird embryo. Ecology 5: 348-362. 


\section{Role of gaseous exchange in egg storage and incubation: O. Onagbesan et al.}

ROMANOFF, A.L. (1960) The avian embryo: structure and functional development. McMillan, Ney York, NY.

ROMANOFF, A.L. (1967) Biochemistry of avian embryo. Interscience Publishers. New York.

ROMANOFF, A.L. and ROMANOFF, A.J. (1933) Biochemistry and biophysics of the developing hen's egg. II. Influence of composition of air. Cornell University, Agricultural experimental station. Bulletin 150: 1-36.

ROMANOFF, A.L. and ROMANOFF, A.J. (1949) The avian egg. John Willey and Sons, New York.

ROQUE, L. and SOARES, M.C. (1994) Effects of eggshell quality and broiler breeder age on hatchability. Poultry Science 73: 1838-1845.

ROUWET E.V., TINTU, A.N., SCHELLINGS, M.W., VAN BILSEN, M., LUYGEN, E., HOFSTRA, L., SLAAF, D.M., RAMSAY, G. and LE NOBLE, F.A. (2002) Hypoxia induces aortic hypertrophic growth, left ventricular dysfunction, and sympathetic hyperinnervation of peripheral arteries in the chick embryo. Circulation 105: 2791-2796.

RUCKMAN, R.N., ROSENQUIST, G.C., RADEMAKER, D.A., MORSE, D.E. and GETSON, P.R. (1985) The effect of graded hypoxia on the embryonic chick heart. Teratology 32: 463-472.

RUIJTENBEEK, K., KESSELS, L.C.G.A., DE MEY, J.G.R. and BLANCO, C.E. (2003) Chronic moderate hypoxia and protein malnutrition both induce growth retardation, but have distinct effects on arterial endothelium-dependent reactivity in the chicken embryo. Pediatric Research 53: 573-579.

RUTHERFORD, P.P. and MURRAY, M.W. (1963).Effect of selected polymers upon the albumen quality of eggs after storage for short periods. Poultry Science 49: 499-505.

SADLER, W.W., WILGUS, H.S. and BUSS, E.G. (1954) Incubation factors affecting hatchability of poultry eggs. Poultry Science 33: 1108-1115.

SAUVEUR, B., FERRE, R. and LACASSAGNE, L. (1967) Conservation d'oeufs de poule sous atmosphere enrichie en gaz carbonique. Action sur les resultats d'eclosion. Annals Zootechnic 16: 351-356.

SEYMOUR, R.S. and VISSCHEDIJK, A.H.J. (1988) Effects of variation in total and regional shell conductance on air cell gas tensions and regional gas exchange in chicken eggs. Journal of Comparative Physiology B 158: 229-236.

SHARMA, S.K., LUCITTI, J.L., NORDMAN, C., TINNEY, J.P., TOBITA, K. and KELLER, B.B. (2006) Impact of hypoxia on early chick embryo growth and cardiovascular function. Pediatric Research 59: 116120 .

SMITH, A.J.M. (1933) Rate of carbon dioxide output by eggs. Dept. Sci. Ind. Research, Camb., Report of the Food Investigation Board for 1932, pp 95-97.

SMITH, M. (1931) The relations between yolk and white in the hen's egg. III. Gas exchange in infertile eggs. Journal of Experimental Biology 8: 312-318.

SOLOMON, S.E. (1991) Egg and eggshell quality. Wolfe Publishing Ltd., London.

STOCK, M.K., FRANCISCO, D.L. and METCALFE, J. (1983) Organ growth in chick embryos incubated in 40\% or $70 \%$ oxygen. Respiration Physiology 52: 1-11.

STOCK, M.K. and METCALFE, J. (1987) Modulation of growth and metabolism of the chick embryo by a brief (72-hr) change in oxygen availability. Journal of Experimental Zoology Supplement 1: 351-356.

STRICK, D.M., WAYCASTER, R.L., MONTANI, J.P., GAY, W.J. and ADAIR, T.H. (1991) Morphometric measurements of chorioallantoic membrane vascularity: effects of hypoxia and hyperoxia. American Journal of Physiology Heart and Circulation Physiology 260: H1385-H1389.

SWANSON, M.H. and HELBACKA, N.J. (1954) Utilizing carbon dioxide vapour-proof packaging in the preservation of shell egg quality. Poultry Science 33: 1084-1091.

TAYLOR, L.W. and KREUTZIGER, O. (1965) The gaseous environment of the chick embryo in relation to its development and hatchability. 2. Effects of carbon dioxide and oxygen levels during the period of the fifth through the eighth days of incubation. Poultry Science 44: 98-106.

TAYLOR, L.W. and KREUTZIGER, O. (1966) The gaseous environment of the chick embryo in relation to its development and hatchability. 3. Effects of carbon dioxide and oxygen levels during the period of the nineth through the twelfth days of incubation. Poultry Science 45: 867-884.

TAYLOR, L.W. and KREUTZIGER, O. (1969) The gaseous environment of the chick embryo in relation to its development and hatchability. 4. Effects of carbon dioxide and oxygen levels during the period of the thirteenth through the sixteenth days of incubation. Poultry Science 48: 871-877

TAYLOR, L.W., KREUTZIGER, O. and ABERCROMBIE, G.L. (1971) The gaseous environment of the chick embryo in relation to its development and hatchability. 5. Effects of carbon dioxide and oxygen levels during the terminal days of incubation. Poultry Science 50: 66-78.

TAYLOR, L.W., SJODIN, R.A. and GUNNS, C.A. (1956) The gaseous environment of the chick embryo in relation to its development and hatchability. 1. Effects of carbon dioxide and oxygen levels during the first four days of incubation upon hatchability. Poultry Science 35: 1206-1215.

TAZAWA, H. (1980) Adverse effect of failure to turn the avian egg on the embryo oxygen exchange. Respiration Physiology 41: 137-142.

TOBITA, K. and KELLER, B.B. (2000) Right and left ventricular wall deformation patterns in normal and left heart hypoplasia chick embryos. American Journal of Physiology Heart and Circulation Physiology 279: H959-H969. 
Role of gaseous exchange in egg storage and incubation: O. Onagbesan et al.

TONA, K., BAMELIS, F., DE KETELAERE, B., BRUGGEMAN, V. and DECUYPERE, E. (2002) Effect of induced molting on albumen quality, hatchability and chick body weight from breeders. Poultry Science $\mathbf{8 1}$ : 327-332.

TONA, K., ONAGBESAN, O., BRUGGEMAN, V., DE SMIT, L., FIGUEIREDO, D. and DECUYPERE, E. (2006) Non-ventilation during early incubation in combination with dexamethasone administration during late incubation. 1. Effects on physiological hormone levels, incubation duration and hatching events. Domestic Animal Endocrinology (in press).

TONA, K., ONAGBESAN, O.M., JEGO, Y., KAMERS, B., DECUYPERE, E. and BRUGGEMAN, V. (2004) Comparison of embryo physiological parameters during incubation, chick quality, and growth performance of three lines of broiler breeders differing in genetic composition and growth rate. Poultry Science 83: 507-513.

TULLETT, S.G. (1978) Pore size versus pore number in avian eggshells. In: Respiratory function in birds, adult and embryonic (Ed: J. Piiper) pp 217-226. Springer, Berlin.

TULLETT, S.G. (1981) Theoretical and practical aspects of eggshell porosity. Turkeys 29: 24-28.

TULLETT, S.G. (1984) The porosity of avian eggshell. Comparative Biochemistry and Physiology 78A: 5-13.

TULLETT, S.G. (1990) The science and art of incubation. Poultry Science 69: 1-15.

TULLETT, S.G. and DEEMING, D.C. (1982) The relationship between eggshell porosity and oxygen consumption of the embryo in the domestic fowl. Comparative Biochemistry and Physiology 72A: 529-533.

VILLAMOR, E., KESSELS, C.G.A., RUIJTENBEEK, K., VAN SUYLEN, R.J., BELIK, J. and BLANCO, C.E. (2004) Chronic in ovo hypoxia decreases pulmonary arterial contractile reactivity and induces biventricular cardiac enlargement in the chicken embryo. American Journal of Physiology Integrative and Comparative Physiology 287: R642-R651.

VINCE, M.A. and SALTER, S.H. (1967) Respiration and clicking in quail embryos. Nature 216: 582-583.

VISSCHEDIJK, A.H. (1985) Gas exchange and hatchability of chicken eggs incubated at simulated high altitude. Journal of Applied Physiology 58: 416-418.

VISSCHEDIJK, A.H.J. (1968a) The air space and embryonic respiration: 1. The pattern of gaseous exchange in the fertile egg during the closing stages of incubation. British Poultry Science 9: 173-184.

VISSCHEDIJK, A.H.J. (1968b) The air space and embryonic respiration: 3. the balance between oxygen and carbon dioxide in the air space of the incubating chicken egg and its role in stimulating pipping. British Poultry Science 9: 197-210.

VISSCHEDIJK, A.H.J. (1991) Gordon Memorial Lecture: Physics and physiology of incubation. British Poultry Science 32: 3-20.

VLECK, D., VLECK, C.M. and HOYT, D.F. (1980) Metabolism of avian embryos: ontogeny of oxygen consumption in the Rhea and Emu. Physiological Zoology 53: 125-135.

WALSH, T.J., RIZK, R.E. and BRAKE, J. (1995) Effects of temperature and carbon dioxide on albumen characteristics, weight loss, and early embryonic mortality of long stored hatching eggs. Poultry Science 74: 1403-1410.

WANGENSTEEN, O.D. and RAHN, H. (1970) Respiratory gas exchange by the avian embryo. Respiration Physiology 11: 31-45.

XU, L.J. and MORTOLA, J.P. (1989) Effects of hypoxia or hyperoxia on the lung of chick embryo. Canadian Journal of Physiology and Pharmacology 67: 515-519. 